Malaysian Journal of Social Sciences and Humanities (MJSSH)

Volume 4, Issue 7, November 2019

e-ISSN : 2504-8562

Journal home page:

www.msocialsciences.com

\title{
Kepimpinan Pengetua Berdasarkan Atribut Semula Jadi dalam Memartabatkan Profesionalisme Keguruan di SMK St Micheal Penampang, Sabah
}

\author{
Rohani Binti Marasan1, Dg. Norizah Ag. Kiflee @ Dzulkifli1, Colonius Atang1 \\ 1Fakulti Psikologi dan Pendidikan, Universiti Malaysia Sabah (UMS) \\ Correspondence: Rohani Binti Marasan (rohanimarasan70@gmail.com)
}

\begin{abstract}
Abstrak
Kepimpinan pengetua diterokai berdasarkan atribut semula jadi yang memfokuskan ketegasan kepimpinan pengetua dalam lapan bidang amalan pengurusan di sekolah. Kerangka teoritikal adalah bersandarkan Teori The Great Man dan model pengetua berkesan diaplikasikan dalam menjalankan kajian secara kualitatif iaitu melalui kajian kes tunggal. Data kualitatif ini diperolehi dengan menemubual pengetua, barisan pentadbir, guru kanan mata pelajaran, dan guru-guru. Data kualitatif dianalisa secara manual. Dapatan menunjukkan atribut semula jadi pengetua berdasarkan aspek ketegasan adalah mencerminkan kewibawaan sikap pengetua dalam amalan pengurusannya di sekolah. Aspek ini diteliti berdasarkan tema demografi pengetua dan pandangan guru-guru. Temu bual mendalam ini menjelaskan amalan pengurusan kepimpinan pengetua dalam lapan bidang utama di sekolah didapati menyokong dapatan sebagaimana dalam teori dibangunkan serta model pengetua berkesan. Bagaimanapun, dalam menghadapi cabaran impak globalisasi, pengetua juga memerlukan sokongan daripada pelbagai pihak sama ada warga sekolah mahupun pihak luar dalam mengurus sekolah dengan lebih berkesan.
\end{abstract}

Kata kunci: cabaran impak globalisasi, kepimpinan pengetua, atribut semula jadi

\section{Principal's Leadership Based on Natural Attributes in Elevating the Professionalism of Teachers at SMK St Michael Penampang, Sabah}

\begin{abstract}
The exploration of Principal's leadership based on the natural attributes is focusing on his/her firmness in eight areas of practice for administration of school. The theoretical framework that applied in this qualitative survey via single case study was formulated using both "Theory the Great Man" and the effectiveness of Principle as a role model. The qualitative data that can be obtained through the interview session with the Principal, administrators, coordinators of subjects, and teachers were analyzed manually. The findings showed that the natural attributes of the Principal in firmness aspect reflecting the integrity of Principal's character in his/her administration practices at school. This firmness aspect was monitored in details based on the demographic of the Principal and point of views of teachers. A detailed interview that conducted during the survey explained that the administration practices of Principal's leadership in eight main areas at school is aligned with the findings from the "Theory the Great Man" and the effectiveness of Principle as a role model. However, in order to face the global impact challenge, the Principal also requires fully support from various parties including the society outside of school in managing the school effectively.
\end{abstract}


Keywords: globalization impact challenge, principal's leadership, natural attributes

\section{Pengenalan}

Kajian tentang kepimpinan pendidikan dilaksanakan untuk memenuhi jurang ilmu bagi membantu penggubal dasar merangka polisi yang berkaitan dengan kepimpinan terutama sekali kepimpinan pengetua. Kepimpinan pendidikan masa kini tidak lagi bertumpu kepada pemimpin sahaja tetapi diaplikasikan kepada memartabatkan lagi profesionalisme keguruan selanjutnya memberikan impak terhadap kemenjadian murid secara holistik. Pendidikan merupakan agenda yang penting dalam membangunkan negara. Kualiti pendidikan adalah penyumbang terhadap pembentukan nilai generasi muda. Kualiti pendidikan yang cemerlang sebenarnya amat bergantung kepada kepimpinan pengetua selaku pemimpin pendidikan. Kualiti inilah yang diharapkan bakal menerajui cabaran impak globalisasi di era digital yang rencam.

Dalam usaha mengapai aspirasi nasional ini, kita seharusnya mampu menyesuaikan diri dengan perubahan globalisasi tersebut. Sekalipun berhadapan pelbagai halangan. Profesionalisme keguruan adalah merupakan profesion yang mencabar dalam penyampaian sosial. Tegasnya, profesion ini memerlukan kepimpinan yang jitu dan mampu membawa kualiti kecemerlangan dalam menghasilkan kemenjadian murid yang holistik. Bagaimanapun, bukan mudah untuk mentadbir urus sesebuah organisasi seperti institusi sekolah yang memiliki kepelbagaian ragam manusia. Justeru, kepimpinan pengetua memainkan peranan penting dalam mencapai hasrat pendidikan.

Di Malaysia, kepimpinan pengetua kini kerap dibincangkan dan dijadikan bahan kajian ilmiah. Pelan Pembanguanan Pendidikan Malaysia (PPPM 2013-2025) menitikberatkan kualiti kepimpinan sekolah dan kualiti guru. Kajian lepas yang mengkaji keberkesanan kepimpinan pengetua dapat dilihat menerusi kajian yang dibuat oleh Bity Salwana Alias, Ahmad Basri Md. Yusof, Ramlee Mustapha dan Mohamad Jani Ibrahim, (2010) menjelaskan bahawa pengetua harus memiliki kompetensi yang diperlukan agar mampu bertindak dengan cemerlang dalam mengurus dan memimpin sekolah.

\section{Pernyataan Masalah}

Fokus kajian ini dilaksanakan adalah untuk meneroka kepimpinan pengetua berdasarkan atribut semula jadi. Perkara ini didasari apabila masih berlaku kemerosotan dalam penilaian antarabangsa iaitu "Trends International for Mathematics and Science Study" (TIMSS) dan "Programme for International students Assessment"(PISA). Kajian kepimpinan pengetua menunjukkan terdapat hubungan dengan prestasi akademik murid yang semakin menurun (Mitchell, Kensler, TschnnenMoran, 2015). Kajian ini memberikan petunjuk bahawa kepimpinan pengetua mempunyai pengaruh terhadap profesionalisme keguruan. Dalam usaha menjayakan sistem pendidikan negara agar setanding dengan dunia luar, kepimpinan pengetua perlu diberikan perhatian utama dilakukan oleh pihak Kementerian Pendidikan Malaysia.

Tujuannya adalah untuk memantapkan sistem pendidikan sedia ada ke arah perubahan globalisasi. Pemantapan ini dimulai oleh kepimpinan pengetua. Anjakan kepada akses dalam PPPM 2013-2025 sebenarnya memerlukan anjakan terhadap transformasi pendidikan agar dapat melahirkan lebih ramai modal insan pengetua yang berwibawa dan berkredibiliti tinggi untuk melaksanakan pengurusan dan pentadbiran yang berkesan di sekolah. Kerancakan perubahan menuntut kebijaksanan kepimpinan merungkai cabaran pengetua juga perlu memainkan peranan sebagai kepimpinan teknologi masa kini sebagai suatu langkah mencapai sekolah berprestasi tinggi. Kajian-kajian ini menjelaskan peranan pengetua perlu bersikap proaktif dan mampu menyesuaikan cabaran semasa agar perkembangan dan kemajuan prestasi sekolah dapat dicapai dengan jayanya.

Profesionalisme keguruan mampu dimartabatkan jika kepimpinan sekolah adalah berkesan melalui peranan pengetua yang memberi penekanan terhadap keperluan pendidikan seperti kepimpinan 
kolaboratif (Wan Noor Adzmin , 2017) yang semakin popular. Kepimimpinan ini memberi peluang kepada guru-guru memperkembangkan karya kerjaya mereka berdasarkan kreativiti dan inovasi yang akan dikongsikan bersama-sama rakan guru dalam pengajaran dan pembelajaran.

\section{Tujuan Kajian}

Kajian ini dilaksanakan untuk meneroka perlaksanaan kepimpinan pengetua berdasarkan atribut semula jadi dalam memartabatkan profesionalisme keguruan.Atribut semula jadi merupakan sifat dalaman seseorang yang mencerminkan kekuatan fizikal dan mental pemimpin. Atribut semula jadi ini akan menjadi amalan terbaik untuk menganalisis sifat kepimpinan yang dimiliki oleh pengetua dalam memartabatkan profesionalisme keguruan di sekolah.

\section{Objektif Kajian}

Kajian ini dilaksanakan untuk mencapai objektif :meneroka kepimpinan pengetua berdasarkan atribut semula jadi dalam memartabatkan profesionalisme keguruan.

\section{Sorotan Literatur}

\section{Atribut Semula Jadi}

Kajian empirikal menyokong pengetua yang berkualiti ditentukan oleh tret personaliti dalam tindakan yang dilakukan (Ishak Sin, 2001). Seterusnya, beliau menyenaraikan sebanyak 29 tret pengetua berkesan (Ishak Sin, 2004). Walau bagaimanapun, di Malaysia masih kurang kajian yang membincangkan tentang tret pengetua sedangkan sekolah amat memerlukan kepimpinan pengetua dalam menghadapi cabaran pendidikan. Pengetua yang memiliki kompetensi dikaitkan mampu meningkatkan prestasi sekolah sama ada dalam akademik, sahsiah dan kemenjadian murid. Pengetua yang memiliki personaliti berkualiti akan mampu berhadapan dengan perubahan pendidikan yang kian mencabar. Perubahan globalisasi merupakan cabaran dan tekanan dalam dunia pendidikan memerlukan pengetua yang bersedia menghadapi risiko sebagai pengetua serta berkeupayaan menjadi pengetua dalam memimpin sekolah ke mercu kecemerlangan.

Kepimpinan pengetua yang semakin kompleks ini diakui lebih mencabar (Hairuddin Mohd Ali, Shariffah Sebran Jamila Syed Imam. Muhammad Sani Hj Ibrahim dan Mohd Izham Hamzah, 2013) turut mengupas tret personaliti pengetua dan guru besar novis di Malaysia merumuskan tahap keyakinan diri, iltizam dan integriti adalah tinggi setelah pengetua dan guru besar diberikan latihan profesional.

\section{Kepimpinan Pengetua}

Transfomasi pendidikan melalui PPPM 2013-2025 adalah bertujuan menambahbaik kepimpinan pengetua di sekolah. Kepimpinan yang berkesan adalah bergantung kepada strategik kepimpinan pengetua di sekolah. Terdapat banyak konsep terkini kepimpinan pengetua yang berjaya seperti kepimpinan transformasi, kepimpinan kolaboratif, kepimpinan distrubatif dan sebagainya. Prestasi sesebuah sekolah akan dapat dipertingkatkan jika adalah budaya kepimpinan pendidikan yang cemerlang. Kepimpinan sebenarnya merupakan alternatif utama yang perlu ditegaskan dalam membina ransangan kepimpinan dalam sesebuah organisasi seperti di sekolah. Adanya kepimpinan pengetua yang berkesan akan mampu memrelisasikan keperluan pendidikan sebagaimana dikehendaki oleh masyarakat.

\section{The Great Man Theory}

Moorhead dan Griffin, 1998 menyebut teori ini dikenal pasti sebelum abad ke-19. pendekatan tret kajian memfokuskan tentang ciri fizikal dan personaliti seseorang pemimpin. Ciri kepimpinan yang hebat dikaitkan dengan ciri semulajadi seperti ketinggian, karaktor dan ciri-ciri kecederasan "he is born 
to be a leader", Great Man (Bass dan Bernard, 1989). Kejayaan seseorang pemimpinan dibuktikan melalui teori yang dikenali sebagai "The Great Man Theory". The Great Man Theory ialah teori berkisar tentang kualiti yang dimiliki oleh manusia yang hebat dan memberikan fokus karaktor seseorang ketua. Kualiti ini berupaya membezakan ketua dan pengikut. Stogdill (1948) menganalisis 124 tret personaliti dikaji dan mendapati terdapat lapan tret mampu dipraktikkan iaitu intelek, kepedulian, mendalami, intutif, bertanggungjawab, memberi perhatian, keyakinan dan suka bergaul. Pandangan klasik bersetuju kepimpinan yang hebat dikatakan memiliki tret personaliti yang tinggi. The Great Man Theory merumuskan mereka yang memiliki tret personaliti tinggi adalah pemimpin semula jadi sama ada dalam kalangan lelaki mahupun wanita (Spector, 2016) Teori tret sering dikaitkan secara langsung dengan keberkesanan pemimpin yang cemerlang dan hebat dalam kepimpinan yang diterajui.

\section{Kajian-kajian Lepas}

Kajian-kajian kepimpinan tentang pengetua masih menarik minat para pengkaji. Perkara ini juga tidak akan berhenti kerana kepimpinan itu sentiasa wujud sifatnya di mana-mana organisasi di dunia ini. Malah, kepentingan peranan serta fungsi kepimpinan merupakan asas dalam sesebuah entiti. Kajian kepimpinan pengetua masih menunjukkan pernyataan individu yang menentukan maju atau mundur sesebuah sekolah. Maka, kajian tentang pengetua sekolah di Malaysia menekankan situasi sistem pendidikan yang berpusat, beban dan akauntibiliti diletakkan kepada pengetua adalah tinggi dan kompleks.

Pengetua di sekolah merupakan ketua jabatan. Kajian tentang kepimpinan pengetua yang dikaji hampir 30 tahun dan pada awal 1970-an. Kajian kepimpinan pengetua telah memfokuskan dalam bidang disiplin dan pengurusan sekolah. Pengetua bertanggungjawab setiap operasi sesebuah sekolah. Malahan pada tahun 1980-an penyelidikan tentang sekolah berkesan mula dikaitkan dengan kepimpinan pengetua dalam mencapai kecemerlangan pelajar dalam akademik. Sehinggalah pada tahun 1990-an kepimpinan pengetua di sekolah dilihat sebagai pemimpin intruksional.

Sebagai pemimpin intruksional, pengetua merupakan individu yang bertanggungjawab untuk memastikan kemudahan di sekolah, kewangan, kualiti guru dan pencapaian pelajar. Pengetua juga dikatakan perlu memperbaiki kemudahan dari aspek kurikulum, arahan dan penilaian. Pengetua adalah bertanggungjawab untuk memantau keberkesanan dalam bilik darjah dan menggalakkan guru yang mengurus bilik darjah adalah guru yang berkebolehan. Dapatan ke atas analisis kompetensi pengetua berdasarkan kualiti peribadi adalah menunjukkan skor yang tinggi (Bity Salwana Alias, Ahmad Basri Md. Yussof, Ramlee Mustapha dan Mohammed Sani Ibrahim, 2010).

Seterusnya, kajian tentang latar belakang pengetua-pengetua di Malaysia masih belum mencukupi (Lokman Mohd Tahir dan Mohd Anuar Abdul Rahman, 2011). Kajian tentang demografi khususnya kalangan pengetua wanita terutama tentang sikap pengetua wanita yang autokratik, akauntabiliti, dan mementingkan nilai kemanusiaan (Amy Smith, 2016) masih belum banyak diterokai. Kelompangan ini perlu dipenuhi melalui kajian kepimpinan pengetua. Di samping itu, kepimpinan distributif juga adalah berpotensi untuk menambahbaik kepimpinan sekolah dengan intervensi organisasi dan program instruksional bagi memartabatkan lagi profesionalisme keguruan.

Dalam kepimpinan tranformasi pengetua juga terdapat kajian perbandingan antara sekolah menengah dan swasta cemerlang mendapati dapatan tahap kepimpinan tranformasi adalah tinggi (Khalip Musa, Hamidah Yusof, Jamal @ Nordin Yunus, dan Sufian Abdul Hamit, 2014). Kajian ini turut disokong berdasarkan dapatan kajian amalan kepimpinan organisasi pembelajaran di sekolah berprestasi tinggi di Malaysia yang merumuskan bahawa kepimpinan distrubatif pengetua mampu menyelesaikan banyak masalah dalam konteks organisasi. Jika diamalkan maka sekolah dan kemenjadian murid mampu dihasilkan. Hujah ini menyokong bahawa kepimpinan pengetua adalah tonggak utama dalam kepimpinan di sekolah.

Pengaruh kepimpinan strategik menunjukkan pengaruh yang tinggi skor dalam kajian kepimpinan (Mua'azam bin Mohammad, 2016). Hujah tersebut merumuskan bahawa kepimpinan pengetua yang 
unggul sama ada kepimpinan tranformasi, distrubatif dan strategik merupakan elemen orientasi kepimpinan pengetua dalam merelisasikan kepimpinannya memacu sesebuah sekolah ke mercu kejayaan. Kajian-kajian lain yang menunjukkan kajian tentang kepimpinan pengetua adalah merujuk kepada atribut pemimpin sekolah menjurus terhadap sifat kepimpinan berkesan adalah pemimpin yang memiliki karaktor baik dan unggul. Dapatan ini disokong juga melalui kajian berdasarkan tiga pesonaliti tret yang dimiliki oleh pemimpin pendidikan iaitu Neuioticism, Extraversion dan Conscionsess ( Hajar Jannesari, Mohammad Reza Iravani, Ahmad Masaeli, Eram Farhaong Dareshori dan Akram Ghorbani, 2013). Kajian Ali Mohd Jubran Saleh, (2014) tentang pengetua di sekolah Islamik di Jordan menyatakan pengetua didapati adalah bersikap positif, kreatif dan signifikan.

Kajian kepimpinan di Indonesia pula menterjemahkan peranan pengetua yang mengamalkan kepimpinan instruksional adalah menunjukkan nilai positif iaitu para guru sentiasa mengikut amalan yang dikehendaki oleh pengetua secara efektif (Yunita Firmaningsih-Kolu, 2015). Kajian ini dijalankan kepada tiga orang pengetua dan tiga orang guru di sekolah yang berbeza melalui temu bual mendalam. Jika diteliti amalan kepimpinan kolaboratif dalam kalangan pemimpinan instruksional yang dijalankan, telah menunjukkan bahawa elemen-elemen kepimpinan kolaboratif diamalkan adalah untuk memacu guru-guru dalam kerjaya keguruan (Wan Noor Adzmin binti Mohd Sabri, 2017).

Kajian ini disokong berdasarkan Standard Kualiti Pendidikan Malaysia (2010). SKPM (2010) mengemukakan empat aspek iaitu hala tuju, pengurusan organisasi, perancangan program pendidikan dan kemenjadian murid. Tujuannya adalah untuk mencerminkan keberkesanan sesebuah sekolah ditadbir oleh pengaruh pengetua dalam melaksanakan tugasnya di sekolah dapat diukur berdasarkan SKPM. Walaubagaimanapun, dalam kajian kualitatif dapatan seperti di atas masih kurang dikaji oleh penyelidik khususnya yang memfokuskan kajian atribut sebagai elemen kepimpinan dalam penempatan pengetua di sekolah menengah. Justifikasi kajian ini dijalankan adalah secara kajian kualitatif kajian kes tunggal bagi meneroka kepimpinan pengetua berdasarkan atribut semula jadi dalam memartabatkan profesionalisme keguruan.

\section{Metod Kajian}

\section{Reka bentuk Kajian}

Kajian ini merupakan kajian kes tunggal berbentuk kualitatif yang mengumpul data menggunakan temu bual mendalam separa berstuktur. Kutipan data adalah memfokuskan kepada pengetua dan barisan pentadbir serta guru-guru.

\section{Pengumpulan Data}

Teknik pengumpulan data iaitu temu bual mendalam, pemerhatian dan analisis dokumen telah digunakan oleh penyelidik. Penyelidik menggunakan protokol temu bual dan pemerhatian bagi memudahkan kerja lapangan. Penyelidik juga merupakan peserta kajian. Seramai 10 orang peserta kajian telah berjaya ditemubual oleh penyelidik.

Pada peringkat awal, penyelidik menggunakan kerangka teoritikal bagi membantu penyelidik membina tema bagi memudahkan kategori data dikumpul data tersebut diketagorikan berdasarkan orientasi pentadbiran di sekolah tersebut. Penyelidik juga menyusun data-data mengikut kategori berdasarkan teori The Great Man.

\section{Pensampelan Kajian}

Dalam konteks kajian ini, penyelidik menggunakan pesampelan bermatlamat (purposive sampling). seramai 10 orang peserta kajian telah dipilih dan mereka adalah terdiri daripada seorang pengetua, tiga orang guru penolong kanan, empat guru kanan mata pelajaran, dua orang guru lelaki dan wanita yang berpengalaman melebihi lima tahun berkhidmat di sekolah tersebut. Peserta kajian ini dipilih berdasarkan kriteria yang dikehendaki oleh penyelidik. Dengan itu kajian ini akan dapat dilaksanakan 
secara berfokus dan data tersebut akan dapat memberikan gambaran jelas terhadap keperluan yang ingin diperolehi melalui kajian ini bagi menjawab objektif kajian.

Jadual 1 Bilangan peserta kajian mengikut kategori

\begin{tabular}{cccc}
\hline Pengetua & Penolong Kanan & Ketua Bidang & Guru \\
\hline 1 & 3 & 4 & 2 \\
\hline
\end{tabular}

\section{Instrumen Kajian}

Bahagian ini membincangkan tiga jenis instrumen kajian yang digunakan iaitu :

\section{a) Temu Bual}

Kajian ini menggunakan teknik temu bual semi berstruktur iaitu peserta kajian akan bebas menyuarakan pola pemikiran mereka tentang kepimpinan pengetua. Semua temu bual yang dikumpulkan akan ditranskripsikan secara vervatim oleh penyelidik. Ketika proses temu bual penyelidik akan menggunakan perakam suara bagi memastikan tiada data yang tercicir dan inilah yang akan ditranskripsikan oleh penyelidik. Sebanyak 10 temu bual dilakukan oleh penyelidik berdasarkan pensampelan ditentukan.

\section{b) Pemerhatian}

Teknik pemerhatian ini adalah menggunakan teknik pemerhatian turut serta iaitu penyelidik akan melakukan pemerhatian di sekolah yang berkisar tentang peristiwa yang berkaitan dengan kepimpinan.

\section{c) Analisis dalaman}

Bagi teknik analisis dokumen penyelidik akan mengumpul semua dokumen yang berkaitan dengan pengurusan seperti minit mesyuarat, laporan program peningkatan prestasi, laporan disiplin dan dialog prestasi yang telah dilaksanakan di sekolah. Ini termasuk juga surat meyurat atau dokumen yang berkaitan daripada Kementerian, JPN atau PPD.

\section{Kesahan dan kebolehpercayaan data}

\section{a) Jejak audit}

Kajian ini melibatkan jangka masa yang lama iaitu selama enam bulan. Data yang dikutip adalah secara kajian kualitatif. Jejak audit digunakan adalah untuk mendapatkan kebolehpercayaan data yang dikutip.

\section{b) Persampelan Bermatlamat}

Pemilihan pesampelan bermatlamat adalah membolehkan penyelidik mendapat data daripada peserta kajian bagi memenuhi kriteria yang dikehendaki oleh penyelidik. Sekolah yang dipilih juga adalah sesuai dengan rekabentuk kajian . Malah, sekolah merupakan kes kajian ini dijalankan.

\section{Kesahan Data}

Bagi kajian kualitatif semakan rakan dan semakan pakar adalah prosedur kesahan yang digunakan dalam kajian ini. 


\section{a) Semakan Rakan}

Peserta kajian akan diminta membacakan semula soalan-soalan yang terdapat dalam protokol temu bual dan transkrip yang telah disediakan oleh penyelidik. Tujuannya adalah untuk memastikan kesepadanan maklumat dan hasil temu bual adalah sama sebagaimana kehendak kajian.

\section{b) Semakan Pakar}

Kajian ini juga akan menggunakan semakan pakar. Kepakaran penyelia kajian adalah diutamakan bagi memastikan penyelidikan mematuhi etika penyelidikan sepanjang penyelidikan dijalankan.Pengesahan data yang dikumpul dengan tema yang sesuai dengan objektif kajian. Semua ini akan ditringulasikan dengan pemerhatian dan analisis dokumen.

\section{Analisis Data}

Tema-tema yang dikenalpasti telah dikategorikan aspek kepimpinan dan aspek strategik yang dilaksanakan. Penyelidik menggunakan tema membina dasar bagi meneroka kepimpinan pengetua berdasarkan atribut semula jadi. Manakala tema menetapkan matlamat adalah meneroka strategik digunakan dalam mendepani cabaran pendidikan yang dapat memartabatkan profesionalisme keguruan. Kesemua tema-tema ini pula diagihkan lagi kepada sub-subtema yang telah dikenalpasti oleh penyelidik menerusi transkrip temu bual.

Jadual 2: Analisis data mengikut kategori, tema dan subtema

\begin{tabular}{llll}
\hline Kategori Penyelidik & Tema & Subtema & Catatan \\
\hline Aspek Kepimpinan & Membina dasar & Kemenjadian Murid & Perancangan Strategi \\
Aspek Strategik & Menetapkan matlama & Pengurusan Sekolah & $\begin{array}{l}\text { Perhubungan guru } \\
\text { dan pemimpin }\end{array}$ \\
\hline
\end{tabular}

\section{Dapatan Kajian}

Dalam meneroka kepimpinan pengetua berdasarkan atribut semula jadi, terdapat dua perkara yang dikaji oleh penyelidik iaitu 'aspek kepimpinan' dan 'aspek strategik' bagi menjawab persoalan kajian seterusnya mencapai objektif kajian.

\section{Aspek kepimpinan}

Berdasarkan dapatan, peserta kajian menyatakan bahawa pandangan penolong kanan pentadbiran iaitu pengetua merupakan pemimpin berwawasan dan mempunyai impian seperti yang ditunjukkan dalam jadual 3 di bawah.

Jadual 3 Dapatan data bagi tema kepimpinan berdasarkan teknik temu bual.

\begin{tabular}{lll}
\hline Peserta Kajian & Temubual & Catatan Analisis \\
\hline PK1 & $\begin{array}{l}\text { Dia seorang yang brillions dan } \\
\text { mempunyai wawasan. Sering dia } \\
\text { sebut ialah kita perlu ada impian. } \\
\end{array}$ & Kualiti Peribadi \\
& {$[\mathrm{P} 1 / \mathrm{TB} / \mathrm{S} 2]$} & \\
\hline
\end{tabular}




\section{Aspek Strategik}

Dapatan dalam jadual 4 menunjukkan pelaksanana strategik pengurusan pengetua dalam memartabatkan profesionalisme keguruan. Pengetua sering menegur guru jika keterampilan peribadi yang tidak mencerminkan etika berpakaian guru, terutama pada hari Isnin. Dalam menangani permasalahan murid, pengetua juga tidak bersifat bertangguh. Ini adalah antara stretegik dilaksanakan bagi menagani cabaran kepimpinan dalam mengurus rutin di sekolah.

Jadual 4 : Dapatan data bagi Tema Strategik berdasarkan teknik temu bual

\begin{tabular}{|c|c|c|}
\hline Peserta Kajian & Temu bual & Catatan Analisis \\
\hline PK 3 & $\begin{array}{l}\text { dia selalu tegur guru yang tidak pakai tali leher pada } \\
\text { hari Isnin. Dia sendiri akan bagi tali leher kepada guru } \\
\text { yang tidak pakai...[PK3/TB/S8] }\end{array}$ & $\begin{array}{c}\text { Kualiti } \\
\text { Peribadi }\end{array}$ \\
\hline PK1 Pengurusan & $\begin{array}{l}\text { sangat pantas pemikirannya }[\mathrm{PK} 1 / \mathrm{TB} / \mathrm{S} 2] \\
\text { Dia tidak suka bertangguh dengan permasalahan } \\
\text { pelajar.. } \\
\text { Dia terus.[PK/TB/S3] } \\
\text { Sangat mahir..headcount pengetua buat.. } \\
\text { [PK1/TB/S5] }\end{array}$ & Strategik \\
\hline
\end{tabular}

Hasil kajian menunjukkan bahawa kepimpinan pengetua berdasarkan atribut semula jadi terpancar daripada starategik dilaksanakan. Dalam aspek kepimpinan, pengetua akan menetapkan dasar dan menetapkan matlamat bagi memastikan kemenjadian murid mampu dicapai.

\section{Perbincangan}

Dapatan kajian juga memfokuskan kepada keperhatian peribadi adalah berusaha untuk menzahirkan pengaruh pesonaliti dan daya kepimpinan daripada kalangan guru. Penemuan yang hebat ini merupakan ekspresi sebenarnya dalam etika keguruan yang menyebut tentang kepentingan keterampilan peribadi guru berupaya menggamitkan minat murid untuk hadir ke sekolah seterusnya menerima pengajaran guru. Bagi penyelidik guru yang luar biasa, berkomited dalam kerjaya semestinya mampu menjaga keperbadian yang mulia.

Dengan pengaruh pesonaliti ini, guru mampu menjadi idola kepada murid dan merekalah yang dikatakan pemimpin pembelajaran. Kepimpinan pengetua berdasarkan atribut semula jadi akan berusaha sehabisnya menekankan peri pentingnya guru-guru di sekolah untuk kekal dengan pesonaliti yang kemas, bersih serta berketerampilan guru semasa di sekolah mahupun ketika berada di luar sekolah.Tujuan pengetua adalah untuk memartabatkan profesioanlisme keguruan agar dipandang tinggi oleh anggota masyarakat terutama sekali para ibu bapa yang menaruh kepercayaan terhadap pendidik.

Objektif kajian iaitu meneroka kepimpinan pengetua berdasarkan atribut semula jadi dalam memartabatkan profesionalisme keguruan, menemui jawapan tentang kepimpinan pengetua dalam menzahirkan program pendidikan dengan mengwujudkan sub tema daripada model insan berkualiti yang mencerminkan pengetua adalah insan yang memiliki sifat peribadi yang tinggi. Seterusnya, pengetua dikatakan mampu meneroka ruang yang luas kepada kepimpinannya yang bertransformasi. Malah, pengetua juga dapat mencapai kejayaan hasil daripada kerjasama semua pihak dalam kepimpinannya. Di samping itu, kejayaan pengetua juga mampu diterokai melalui kebijaksanannya mengkoordinasikan aktiviti pendidikan.

Penerokaan strategik terhadap kepimpinan pengetua. Guru-guru diteliti mempunyai persepsi yang positif. Bagi kalangan guru yang enggan menerima transformasi kepimpinan pengetua, mereka ini akan sentiasa diberi teguran dan nasihat secara peribadi atau dimaklumkan dalam mesyuarat guru. Dapatan 
membuktikan bahawa kejayaan transformasi akan membawa impak positif kepada guru untuk berkerja bersama-sama pengetua selaras dengan dasar dan pekeliling yang ada. Pengetua berjaya menggambit kesungguhan guru untuk bekerja secara ikhlas melalui pendekatan kemanusiaan yang diamalkan.

Akhir sekali, dapatan membuktikan bahawa kepimpinan pengetua berjaya menjadi pendorong kepada kemenjadian murid sebagai penentu prestasi dalam pelbagai penemuan kajian. Maka, diharapkan kajian ini memberi inspirasi kepada semua pihak dalam menilai kepimpinan pengetua berdasarkan atribut semula jadi dalam memartabatkan profesionalisme keguruan.

\section{Kesimpulan}

Kajian ini memaparkan kepentingan kepimpinan pengetua yang dilaksanakan di sekolah menengah terpilih di negeri Sabah iaitu SMK St Micheal Penampang. Sekolah ini menjadi kes kajian ini yang merujuk kepada pencapaian sekolah dan sebuah sekolah kluster kecemerlangan Kepimpinan pengetua adalah wahana pemangkin kepada transformasi kepimpinan di sekolah. Kajian ini dikembangkan menggunakan pendekatan epistomologi tentang kepimpinan pengetua yang didasari oleh atribut semula jadi yang merupakan kekuatan dalaman seseorang mampu membangkitkan motivasi dalam menjayakan kepimpinan pengetua. Dengan kekuatan atribut semula jadi, seseorang penegtua itu akan melaksanakan tugasnya dengan bersungguh, ikhlas serta tabah.

Kejayaan dalam sesebuah sekolah adalah melalui strategi yang diamalkan dan dicorakkan menerusi kepimpinan pengetua yang cemerlang juga dapat memberikan dorongan motivasi akan berupaya membuahkan kerjasama guru-guru. Perkara ini amatlah bertepatan dengan keperluan di era digital yang memerlukan kreativiti dan inovasi dalam kalangan pendidik. Justeru, kajian kepimpinan pengetua adalah menarik dan unik untuk dibangunkan sebagai sebuah kajian bagi menambahbaik amalan pentadbir pendidikan terutama kalangan pengetua.

Usaha dalam meningkatkan kemampuan kepimpinan pengetua dalam segala perkara perlu terus dilakukan agar segala sistem dan dasar-dasar pendidikan mampu direalisasikan dan juga ia sebagai usaha untuk memartabatkan profesionalisme keguruan agar dapat membangunkan, memajukan dan mencipta kejayaan demi kejayaan dalam pencapaian sekolah pada setiap masa.

\section{Rujukan}

Amy Smith, 2018. Organizational Leadership Department.Proquest February 2018.

Bass dan Bernard, 1989. Handbook of leadership : A Survey of Theory and Managerial Application. New York. Free Press.

Bity Salwana Alias, Ahmad Basri Md. Yussuf, Ramlee Mustapha dan Muhammad Jani Ibrahim, 2010, Analisis kompetensi Pengetua berdasarkan kualiti peribadi, kemahiran dan amalan dalam bidnag pengurusan sekolah menengah Malayisa. Journal Pendidikan Malaysia 35 (2) (2010), 31-41.

Firmaningsih-Kolu, Yunita. 2015. The Role of the Principals Instructionl Leadership at Schools in Indonesia.

Siti Uzairiah, 2018. Mudahnya Kajian Literatur. Reezqi Publication Selangor.

Siti Uzairiah, 2017. Kajian Kualitatif dan Analisis Temu bual. Aras Publisher Kuala LumpurMalaysia.

Hallinger, Philips and Murphy. J.F 1987. Assessing and Developing Principals Instructional Leadership. Educational Leadership. Sept.54-61.

Great Man Theory. A Personal Account of Attraction. Paper for the IBA Confference. Helen L. Echmann. National University Diego.

Hairuddin Mohd Ali, Shariffah Sebran Jamila Syed Imam. Muhammad Sani Hj Ibrahim dan Mohd Izham Hamzah, 2013. Tret Personaliti Pengetua dan Guru Besar Novis di Malaysia.

Ishak Sin, 2001 . Intitut Aminuddin Baki. Kementerian Pendidikan Malaysia.

Ishak Sin, 2004. Apakah yang tertulis dalam khazanah tulisan ilmiah tentang tret, tingkah laku dan tindakan diperlukan untuk menjadi seorang pengetua yang berkesan. Journal Pengurusan dan Kepimpinan Pendidikan 14(1):1-17. 
Jemaah Nazir (2001) Pernyataan Dasar Standard Tinggi Kualiti Pendidikan (SKTP) Kuala Lumpur. James Sebatian, Haigen Huang dan Elaine Allesworth, (2017). Examining Intergrated Leadership System in High School : Conneting Principal and Teacher Leadaership to Organizational Process and Students Outcome. Journal Http://www.Tndfonlime.com

James Ang Jit Eng. (2018). Kepimpinan Knstruksional . Satu Panduan Praktikal. PTS Professional. Kuala Lumpur.

Jamilah et al ,2011). Amalan Kepimpinan Sekolah Berprestasi Tinggi (SBT) di Malaysia. Journal of Edupress, $1323-335$

Lokman Mohd Tahir dan Mohd Anuar Abdul Rahman,2011. Orientasi Kepimpinan Sekolah Menengah di Johor : Satu Analisis. Jurnal Teknologi, 48€ Jun 2008: 85-97 . UTM.

Moorhead dan Griffin, 1998. Organizational behavior : managing people and organizational. Ed ke-5 Boston: Houghton Miffin Co.

Micheal Quinn Patton (2002) Qualitative Research and Evalution Methods. 3 Edition. Sage Publications.

Miles . M. b and Huberman A.M 1994. Qualitative Data Analysis.

Merriam, Sharan B. 2009. Qualitative Research :A Guide to Design and Implementation San Francisco. Jossey Bass.

Mua'azam bin Mohammad, Yahya bin Don dan Siti Noor bt. Ismail, 2016. Kepimpinan Strategik dan Hubungannya dengan Kesediaan Peubahaan Warga Organisasi. Jurnal Kepimpinan, April 2016. Bil 3 Isu 2.

Malaysia K.P. 2010. Standard Kualiti Pendidikan Malaysia, 2010. Nazir dan Jaminan Kualiti KPM, 2010.

Nurul Hudani Md. Nawi, Ma'rof Redzuan dan Noor Hisham Md. Nawi, 2016. Jurnal Psikologi Malaysia 30 (1) (2016) ; 102-112ISSN-2289-8174

Phillip Hallinger, Shengnen Liau dan Parnaree (2017). Http://dol.org/101080/0305 $7925: 2017$

Pelan Pembangunan Pendidikan Malaysia (PPPM ), (2013-2025). KPM.

Robert K. Yin, 2018,. Case Study Researh Design and Methods. Third Edition. Sage Publications.

Roxanne M, Mitchell, Lisa A.W.Kensler and Megan Tschannen-Moran, 2015. Examining Effects Instructional leadership on School Academic Press and Students achievement. Http://doi.org/10.1177/10526846.

Stogdill, R (1974). Handbook of Leadership A Servey of Theory and Reasearch. New York .The Free Press.

Sharifah Madinah bt. Syed Abdul Rahman, (2007). The Principal Factor. Sasbadi Selangor Malaysia. Yin, R.K (2003) Case Study Research, Design and Method. Sage. Thousand Oaks. California.

Wan Noor Adzmin binti Mohd Sabri dan Suria Baba. (2017) Julai. Jurnal Kepimpinan Pendidikan IPG kampus Pendidikan Teknik KPM 